\title{
Modelling Electricity Price Expectations in a Day-Ahead Market: A Case of Latvia
}

\author{
Viktorija Bobinaite ${ }^{1}$, Jānis Zuters ${ }^{2}$ \\ ${ }^{1,2}$ University of Latvia
}

\begin{abstract}
The paper aims at modelling the electricity generator's expectations about price development in the Latvian day-ahead electricity market. Correlation and sensitivity analysis methods are used to identify the key determinants of electricity price expectations. A neural network approach is employed to model electricity price expectations. The research results demonstrate that electricity price expectations depend on the historical electricity prices. The price a day ago is the key determinant of price expectations and the importance of the lagged prices reduces as the time backwards lengthens. Nine models of electricity price expectations are prepared for different natural seasons and types of the day. The forecast accuracy of models varies from high to low, since errors are $7.02 \%$ to $59.23 \%$. The forecasting power of models for weekends is reduced; therefore, additional determinants of electricity price expectations should be considered in the models and advanced input selection algorithms should be applied in future research. Electricity price expectations affect the generator's loss through the production decisions, which are made considering the expected (forecasted) prices. The models allow making the production decision at a sufficient level of accuracy.
\end{abstract}

Keywords - Adaptive expectations, electricity, neural network, price, production decision making, profit.

\section{INTRODUCTION}

The concept of expectations is a key element of the behavioural economics (Chow, 2011) and refers to the anticipation or belief about the future of variable, such as commodity price, inflation, interest rates, wage, etc. (BN Vocabulary, 2016). J. F. Muth (1961) suggests that "expectations, since they are informed predictions of future events, are essentially the same as the predictions of the relevant economic theory".

The topic of the price expectations has been well documented in the scientific literature. The theoretical background of price expectations was laid by M. Ezekiel (1938), R. M. Goodwin (1947), M. Nerlove (1958), J. F. Muth (1961), R. E. Lucas (1976), etc. The methodological insufficiencies of the adequate measurement of the expectations were solved by G. de Menil \& S. Bhalla (1973), D. K. Pearce (1975), G. W. Evans \& G. Ramey (2006), D. Demery \& N. W. Duck (2007), etc. The issues of the measurement of the price expectations in the electricity market by applying various forecasting methods were tackled by J. C. Cuaresma et al. (2004), R. Weron \& M. Misiorek (2008), S. Schlueter (2010), Z. Tan et al. (2010), O. Abedinia et al. (2015), etc. S. Aggarwal et al. (2009) and R. Weron (2014) summarised the methods applied to forecast electricity prices. The determinants of price expectations were presented by
J. F. Muth (1961) and M. D. Johnson (1995). A comprehensive review of the determinants that could be used to analyse electricity price expectations was performed by S. Aggarwal et al. (2009). Recently, the number of papers that could be related to the topic of modelling of price expectations in the electricity market have been increasing (Bobinaite \& Konstantinavičiūtè, 2012; Catalão et al., 2007; Vahidinasab et al., 2008; Chogumaira \& Hiyama, 2011; Keynia, 2012; Dev \& Martin, 2014; Anbazhagan \& Kumarappan, 2014; Al-Shakhs \& El-Hawary, 2015; etc.). Practically, these are the papers providing empirical evidence of the key factors forming electricity prices and the relevant methods to forecast prices. Papers are rather technical and are lack of relation to the production decision making and the results of economic performance.

Consequently, it has to be acknowledged that so far there is a shortage of an integrated approach to the price expectations in the electricity market, although practical and scientific reasons exist.

From the practical point of view, the electricity price expectations are important to analyse seeking to facilitate the process of the electricity production decision making, as it was argued by Knoll and Engels (2012), as well as Panapakidis and Dagoumas (2016). From the scientific viewpoint, the analysis of the topic is relevant seeking to solve the methodological insufficiencies by binding into the entire system the fundamentals of electricity prices, the electricity price forecasting methods, the decision making and the results of economic performance. The practical and scientific reasons are the motivating factors for a deeper research in the area of electricity price expectations.

Thus, this paper covers the following questions: what are the determinants of electricity price expectations, how to measure price expectations and how do the electricity price expectations impact the electricity production decision and thereinafter the generator's profit?

The paper aims at modelling the electricity generator's expectations about electricity price development in short-term and disclosing their role in the process of electricity production decision making and thereinafter determining their effect on the profit/loss of generators, who participate in a competitive market.

To achieve the aim, the following tasks are set:

- to identify the key determinants of the electricity price expectations;

- to review the methods used to model electricity price expectations; 
- to model the electricity price expectations based on the theory of adaptive price expectations and the neural network approach;

- to disclose the role of electricity price expectations in the process of production decision making and hereinafter their effect on the generator's profit/loss.

The literature review, statistical data, correlation and sensitivity analysis methods and the method of neural network are used to achieve the aim and accomplish the tasks of the paper.

\section{LITERATURE REVIEW}

\section{A. The Theories of Price Expectations}

The theories of price expectations started being developed in the first half of the past century, when it was explicitly perceived that in an uncertain world the decisions were mostly made taking into account the expectations. Recently, several types and theories of price expectations have been known. They are classical, normal and extrapolative - regressive price expectations and the theories of adaptive and rational expectations.

The evidence of the classical price expectations is found in the work of M. Ezekiel (1938). The scientist discussed the "cobweb theorem" and showed how prices move towards the equilibrium. Following the graphical representation of the "cobweb theorem" and the reasoning about the behaviour of the economic agents, M. Ezekiel (1938) inferred that the expected price of the commodity was equal to its latest price. This is also known as the static or "naive" price expectations (Thiemer, 2007). The mathematical expression of the classical price expectations is provided in (1):

$$
p_{t}^{\mathrm{e}}=p_{t-1},
$$

where $p^{\mathrm{e}}{ }_{t}$ is the expected price in time $t ; p_{t-1}$ is the price in time $t-1$.

The conception of the normal price expectations extends the concept of the classical price expectations by introducing the "normal" price towards which the current price of the commodity moves (Thiemer, 2007). The mathematical expression of the normal price expectations is provided in (2):

$$
p_{t}^{\mathrm{e}}=p_{t-1}+\delta\left(p_{\mathrm{n}}-p_{t-1}\right)
$$

where $p_{\mathrm{n}}$ is the "normal" price, which is the price the generator thinks sooner or later will be in the market; $\delta$ is the speed of price movement towards the "normal" price ( $\delta$ is between 0 and 1).

The insights into the extrapolative - regressive expectations could be found in the work of Goodwin (1947), where the price expectations depend on the historical prices of the commodity. The mathematical expression of the extrapolative - regressive expectations is provided in (3):

$$
p_{t}^{\mathrm{e}}=p_{t-1}+\gamma\left(p_{t-1}-p_{t-2}\right)
$$

where $p_{t-2}$ is the price in time $t-2 ; \gamma$ is the coefficient of error adjustment, which is between -1 and +1 .

Equation 3 shows that the expected price is formed from the observed past price and a particular portion of the most recent price change. Depending on the sign of $\gamma$, the expectations are extrapolative $(\gamma>0)$ or regressive $(\gamma<0)$.

The theory of adaptive expectations presented by M. Nerlove (1958) assumes that the economic agents form their expectations about what will happen with a price in future based on what has happened in the past. Specifically, the economic agents take an assumption that the future price depends only on the price in the past. The mathematical expression of the theory has several forms, which are provided in (4) and (5):

$$
\begin{gathered}
p_{t}^{\mathrm{e}}=p_{t-1}^{\mathrm{e}}+\lambda\left(p_{t}-p_{t-1}^{\mathrm{e}}\right) \\
p_{t}^{\mathrm{e}}=\lambda p_{t}+\lambda(1-\lambda) p_{t-1}+\lambda(1-\lambda)^{2} p_{t-2}+\lambda(1-\lambda)^{3} p_{t-3}+\ldots,
\end{gathered}
$$

where $p^{\mathrm{e}}{ }_{t}$ is the expected price - the next year's price that is currently expected (at time $t$ ); $t$ is time when expectations are formed or actual price is set; $p_{t-1}^{\mathrm{e}}$ is this year's price that was expected in the previous year; $p_{t}$ is this year's actual price; $\lambda$ is the coefficient of the revision of price expectations (Mlambo, 2012) or a learning parameter determining the speed with which the errors are adjusted (Shepherd, 2012). $\lambda$ lies between 0 and 1 .

Equation 4 shows that the expected price is a sum of the expected price in the past and the adjusted expectational error. When the economic agents form new price expectations $\left(p^{\mathrm{e}}{ }_{t+1}\right)$, they revise the expectations made in the past $\left(p_{t}^{\mathrm{e}}\right)$ by current expectational error $\left(p_{t+1}-p_{t}^{\mathrm{e}}\right)$, which is adjusted by the coefficient of revision $(\lambda)$. If the economic agents exactly anticipated the price in the past (i.e., $p_{t}^{\mathrm{e}}=p_{t+1}$ ), then a zero expectational error is achieved, i.e., the price expectations will be hold until the exogenous factors alter the actual price.

The solution of (4) gives a new form of the adaptive expectations (5). Equation 5 shows that all price expectations formed in the past and past actual prices are embodied in the current price expectations. It is suggested to analyse the price expectations as a weighted sum of past actual prices, when weights decrease looking backwards to the past.

Depending on the value of the coefficient of revision $(\lambda)$, several types of adaptive expectations exist (Table I).

TABLE I

TYPES OF ADAPTIVE EXPECTATIONS (SHAHRAM FATTAHI GAKIEH, 2008; MLAMBO, 2012)

\begin{tabular}{|l|l|l|}
\hline $\begin{array}{c}\text { Types of adaptive } \\
\text { expectations }\end{array}$ & $\begin{array}{c}\text { The coefficient of } \\
\text { revision }\end{array}$ & \multicolumn{1}{c|}{$\begin{array}{c}\text { Equation of price } \\
\text { expectations }\end{array}$} \\
\hline Autonomous & $\lambda=0$ & $p^{\mathrm{e}}{ }_{t}=p^{\mathrm{e}}{ }_{t-1}$ \\
\hline Static & $\lambda=1$ & $p_{t}^{e}=p_{t}$ \\
\hline Induced & $0<\lambda<1$ & $p_{t}^{\mathrm{e}}=p_{t-1}^{\mathrm{e}}+\lambda\left(p_{t}-p_{t_{t-1}}^{\mathrm{e}}\right)$ \\
\hline
\end{tabular}


The greater $\lambda$ is, the more significant is the impact of the historical price on the price expectations. The static adaptive expectations assume that there is a permanent shift in the price formation process, thus $\lambda=1$, and the economic agents expect that the price in time $t+1$ will be the same as it was in time $t$. The autonomous adaptive expectations assume that expectational error is random; thus, there is no error adjustment (i.e., $\lambda=0$ ), and the economic agents will not change their expectations about the price. The economic agents will change price expectations if they observe a difference between what they expected about the price for time $t$ and what actually happened with the price in time $t$.

The theory of adaptive expectations is criticised due to several reasons. Firstly, an assumption that price expectations are sensitive to a single factor, i.e., past price, seems too simple and "less logically satisfactory" (Mlambo, 2012) than assumptions of the competing theory of rational expectations. As it was observed by J. F. Muth (1961), the "expectations generally underestimate the extent of changes that actually take place". This is because not all relevant information is taken into account when modelling the adaptive expectations. Secondly, the theory of adaptive expectation postulates that $\lambda$ is constant or time-varying (Shepherd, 2012). L. Mlambo (2012) suggests allowing $\lambda$ varying without an upper bound and among the groups of the economic agents. Thirdly, the critics of the theory disagree with an argument that the economic agents are good statisticians and, therefore, are capable of providing reliable forecasts based on which expectations are assessed. They suggest putting more efforts and testing a validity of the developed models (Mlambo, 2011). Fourthly, due to the retrospection, the theory cannot assess the impact of the announced future policies (Muth, 1961; Lucas, 1976; Shahram Fattahi Gakieh, 2008).

The theory of rational expectations, which was first proposed by J. F. Muth (1961) and accelerated the speed with the critique of R. E. Lucas (1976), is suggested to be called not a school of the economic thought, but instead "an ubiquitous modelling technique used widely throughout economics" (Sargent, 2008). The theory differs from the ones discussed above in a way it determines the relationship between price and price expectations. The mathematical expression of the theory of rational expectations is provided in (6):

$$
p_{t}=p_{t}^{\mathrm{e}}\left(I_{t}\right)=p^{*}
$$

where $p^{*}$ is the equilibrium price; $I_{t}$ is information set used to form price expectations in time $t$.

The hint to the explanation of (6) is found in the work of J. F. Muth (1961), where he used the concept of rational expectations to describe the economic situations in which the result (for example, price) depends on what the economic agents expect to happen. He asserted that because of its scarcity, information was not wasted by the economic system and the expectations depended on the structure of the entire system describing the economy. J. F. Muth's (1961) assumptions proclaim that the economic agents use all information when forming price expectations (Shahram
Fattahi Gakieh, 2008), i.e., price expectations are conditional on the information set $I_{t}$. If information hold by the economic agents allows expecting price increase, then buyers will start purchasing and sellers - limiting supply of the commodity now. When doing so the economic agents adjust the price by increasing it. Thus, a new equilibrium is reached (Johnson, 1995 ) and an adjusted price is set. A new adjusted price is the market's best forecast of the future price (Sargent, 2008). From the viewpoint of sophistication and profundity of the underlying economic statements, the theory is simple; however, applied methods complicate the implementation of the theory in practice.

\section{B. Approaches for Modelling of Expectations}

The approaches that could be used to model price expectations make a tight reference to the methods of price forecasting. Namely, the price forecasts received from the application of the forecasting method could be taken by the economic agents as a proxy to draw the inferences about the expected price (Binder, 2016). The established link between the forecasted and expected prices suggests that price expectations could be modelled by applying the methods of price forecasting. These are qualitative and quantitative methods.

Qualitative methods are a group of intuitive forecasting methods strongly referring to the human factor, i.e., in a subjective opinion of experts, their knowledge and intuition about the price changes in future. The methods are recommended to use when the future of the price cannot be explicitly decided by using other methods, because they are not accurate (Bartkiene, 1993) and in cases of data shortage (Janeliūnas \& Kasčiūnas, 2007). A detailed description of the methods is found in the studies of R. D. Anderson et al. (2009) and J. C. Armstrong \& K. C. Green (2010).

Quantitative methods are a large group of forecasting methods, which refer to the analysis of relationships between the historical prices and the factors forming them. When applying the forecasting methods, an assumption that fixed past tendencies will persist in future is taken. Electricity price forecasting is performed by applying a variety of forecasting methods. A comprehensive review of the methods is provided in the studies of S. K. Aggarwal et al. (2009) and R. Weron (2014).

Game theory (equilibrium) models draw inferences about the price expectations through the analysis of the established price formation process, which matches the demand and supply in a particular type of the market, and the strategic bidding behaviour. The models are used to forecast prices in the hypothetical markets, which yet do not have historical prices, but market participants are interested in whether or not prices will be above the marginal cost and how this will influence the profit of participants. The models consider a lot of elements (participants, their strategies and interactions); thus, there is a price modelling risk. Moreover, the models suffer problems under the request of highly accurate electricity price forecasts in quantitative terms. The game theory models were applied in works of W. Lise \& G. Kruseman (2008), M. Bonacina \& F. Gulli (2008) and M. Tanaka (2009). 
The fundamental models are based on the bottom-up approach (Keles et al., 2016) and aim at representing the electricity production, consumption and trading processes in the model at a very high level of accuracy. They are used to model prices in the authentic power sectors and markets. For this purpose, a large amount of actual data about fundamental factors such as demand pattern, production and transmission capacities and outages, fuel costs, production efficiency, $\mathrm{CO}_{2}$ emission prices, electricity cross-border flows and other data are used. Precise physical and economic relations closely reflecting the reality are established through sophisticated mathematical equations. Thus, these are the parameter-rich models. Since a large amount of information is required to construct a fundamental model, it is used to model mediumand long-term electricity prices rather than short-term. The fundamental model was applied to assess the marginal costs in the German wholesale electricity market by H. G. Schwarz \& Ch. Lang (2006). In Latvia, a new approach to forecast energy sector based on the system dynamics was developed (Skribans \& Balodis, 2016).

Reduced-form models (Markov regime switching and jumpdiffusion) were developed to capture the specific features (spikes, volatilities, mean-reversion, etc.) of electricity prices. Results of the modelling provide a realistic picture of the price dynamics and are usually used for derivative pricing and risk analysis (Weron, 2014). The examples of application of the reduced-form models are found in works of $\mathrm{R}$. Weron \& A. Misiorek (2008).

Time series methods are used to forecast electricity prices by using past electricity prices and past values of factors forming electricity price. In many time series models, electricity consumption and production data are used as input. Depending on a variety of factors, the time series models are univariate and multivariate. Time series models are found attractive, since the relations set in the models help better understand the behaviour of electricity price, and models capture features of electricity prices (spikes, volatility, nonstationarity, etc.) at a sufficient level of accuracy and provide good performance. However, time series methods are criticised due to their weak relation with the economic theories and a limited ability to model a non-linear behaviour of the electricity price. ARIMA, GARCH and regression models, their modifications and combinations are the most common time series methods. Time series methods are applied in the works of J. C. Cuaresma et al. (2004), R. Weron \& A. Misiorek (2008), S. Schlueter (2010), Z. Tan et al. (2010) or V. Bobinaitė \& I. Konstantinavičiūtè (2012).

During recent years, the number of papers on the application of neural networks to forecast electricity prices has considerably increased. This is due to the advantage of the neural network to model a non-linear behaviour of electricity prices (Weron, 2014), a clear and easy implementation with a good performance (Al-Shakhs \& El-Hawary, 2015) and its feature to be less time consuming (Vahidinasab et al., 2008). However, neural networks have limitations. They arise from the neural network's disadvantage to capture some features of the electricity prices at a high level of accuracy.
J. P. S. Catalão et al. (2007) found that a neural network is valuable to forecast electricity prices only during stable periods. D. Singhal \& K. S. Swarup (2011) demonstrated a reasonable accuracy of the neural network to forecast electricity prices during the days with normal trends, but a reducing accuracy during the days with price spikes. The scientists observed that price spikes could be more accurately forecasted by including additional determinants. The neural networks are criticised because of a lack of theoretical background and a systematic procedure for the construction of the model. As a consequence, the construction of the model involves the experimental selection of a wide number of parameters by trial and error (Moreno et al., 2011). Three- and four-layered feed-forward neural networks are the most common architecture (Catalão et al., 2007; Singhal \& Swarup, 2011; Chogumaira \& Hiyama 2011; Dev \& Martin, 2014). Cascaded neural networks are also used (Amjady \& Keynia, 2009; Abedinia et al., 2015). Theoretically, the neural networks could take into account a variety of inputs (Keles et al., 2016); however, the research results demonstrated that lagged prices (Catalão et al., 2007; Vahidinasab et al., 2008; Anbazhagan \& Kumarappan, 2014; Al-Shakhs \& El-Hawary, 2015) and a combination of lagged prices and demand of electricity (Chogumaira \& Hiyama, 2011; Keynia, 2012; Dev $\&$ Martin, 2014) are the most relevant inputs to the models, which improve the accuracy of forecasts.

Thus, it could be stated that the price expectations could be modelled by various electricity price forecasting methods, which differ in sophistication of mathematical apparatus, inputs included, time consumed, etc. However, neural networks are recognised as an advanced method to model nonlinear behaviour and are widely applied in practice.

\section{METHODOLOGY}

\section{A. Data}

Data necessary for the research are collected from the database of Nord Pool Spot (2016). Data cover the period from 3 June 2013 to 9 February 2016. Hourly electricity prices formed in the day-ahead electricity market in Latvia are collected. All data (23568 observations) are divided into four subsets: $50 \%$ of data are used to train, $25 \%$-to select, $24.9 \%$ - to test the network, and the remaining $0.1 \%$ are used to forecast electricity prices. During the model construction phase, the training, selection and test subsets are used. The remaining subset is used during the model application phase.

\section{B. Method for the Input Selection}

As stated by D. Keles et al. (2016), the first and most critical step of the model construction is the selection of inputs and their preparation. As a number of inputs increase, the complexity of the model also increases and this leads to poor convergence (Anbazhagan \& Kumarappan, 2014). Thus, the selection of a relevant set of inputs is of high importance.

A correlation analysis method is used to select the inputs for the model, as it was suggested by V. Vahidinasab et al. (2008). The aim of this task is to eliminate inputs that are not effective, make the model technically sophisticated and large. 
The results of the correlation analysis show that electricity price is correlated with the historical prices $P_{t-24}, P_{t-48}, P_{t-72}$, $P_{t-96}, P_{t-120}, P_{t-240}, P_{t-360}$ and $P_{t-480}$. Correlated data in a correct style and format are supplied to the neural network, as it was suggested by M. Al-Shakhs \& M. E. El-Hawary (2015).

\section{Method of the Neural Network}

A multi-layered perceptron $(M L P)$, which is known as one of the most popular network types (Panchal et al., 2011), is chosen for the construction of model of electricity price expectations. The MPL network type is selected due to its features and advantages (Chen \& Billings, 1992; Panchal et al., 2011; Moreno et al., 2011):

- ability of correct learning of complex input-output mappings using historical data so that the model could later be used to produce the output;

- ability of fitting the linear and non-linear functions without the need for knowing the shape of the underlying function a priori;

- ability of guaranteeing that a one-hidden-layer network is sufficient to represent any arbitrary continuous function;

- a universal model for non-linear systems;

- easily applied, require less training time and provide a good performance.

The key disadvantage is that the MLP trains slowly and requires a lot of training data (usually three times more training samples than network weights) (Panchal et al., 2011).

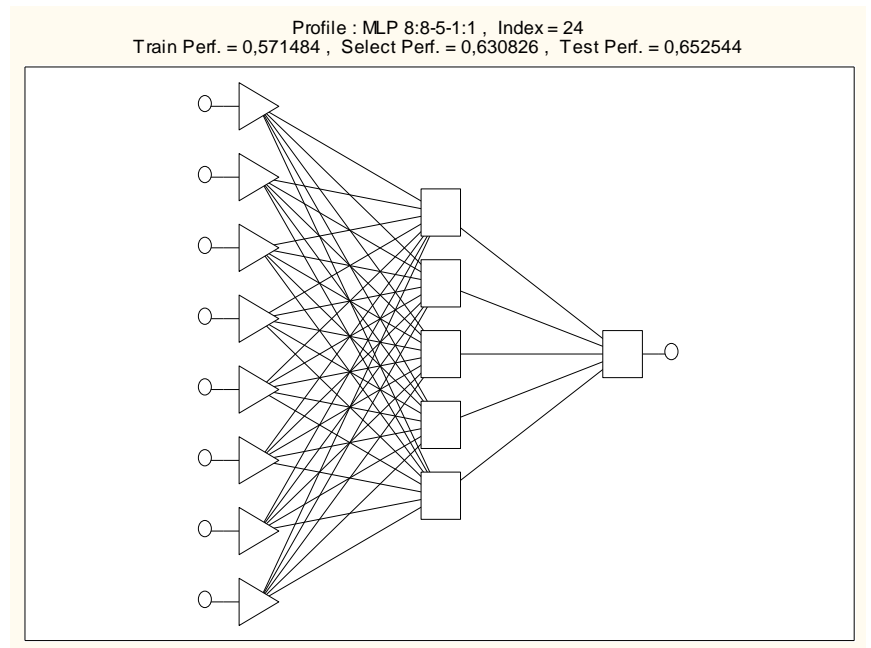

Fig. 1. An example of a two-layered feed-forward neural network model for the quantification of electricity price expectations.

The architecture of the MLP (Fig. 1) is composed of an input, one hidden and output layers. Each layer consists of a certain number of units. The number of units in the input layer is chosen based on the results of the correlation analysis. The number of units in the hidden layer is chosen by trials and errors, selecting several options and then running simulations to find the network with the best results, as it was done by J. P. S. Catalão et al. (2007). The output layer consists of a single unit, which is the electricity price.
The MLP units across the layers are interconnected in a way that interconnections do not form any loops. This is a feedforward interconnection pattern, which was applied in the works of J. P. S. Catalão (2007), N. Chogumaira \& T. Hiyama (2011), S. Anbazhagan \& N. Kumarappan (2014) and M. Al-Shakhs \& M. E. El-Hawary (2015).

Units in the layers have their synaptic and activation functions (see Table II).

TABLE II

SYNAPTIC AND ACTIVATION FUNCTIONS

\begin{tabular}{|l|l|l|}
\hline \multicolumn{1}{|c|}{ Layer } & \multicolumn{1}{|c|}{ Synaptic function } & \multicolumn{1}{c|}{ Activation function } \\
\hline Input & Dot Product & Identity, $f(s)=s$ \\
\hline Hidden & Dot Product & Hyperbolic, $f(x)=\frac{e^{s}-e^{-s}}{e^{s}+e^{-s}}$ \\
\hline Output & Dot Product & Identity, $f(s)=s$ \\
\hline
\end{tabular}

The Dot Product synaptic function is used to compose a scalar value $(s)$ from input information $\left(x_{1}, x_{2}, \ldots, x_{n}\right)$ and their synaptic weights $\left(w_{1}, w_{2}, \ldots, w_{n}\right)$ by multiplying them and summing the resulting values. This function is applied to all layers.

An activation function is applied to the results of the Dot Product. Input and output layers do not have activation functions, i.e., they have a linear identity function subject to which an activation level is passed directly as an output. Hyperbolic activation function is applied to a hidden layer.

The MLP is trained using a two-phase algorithm. During Phase I, a back-propagation algorithm is used. This is a simple algorithm with slow terminal convergence but good initial convergence. During Phase II, a conjugate gradient descent algorithm is used. This is an algorithm with fast convergence.

At the beginning of training, the weights are initialised applying the method of random Gaussian, i.e., the weights are initialised to a normally distributed random value within a range whose mean is 0 and standard deviation is 1 . During Phase I, weights are adjusted by a learning rate of 0.001 , which is experimentally decided. Momentum of 0.3 is used to compensate slow convergence when weight adjustments are consistently in one direction. Momentum increases the speed of convergence of the back propagation.

The number of epochs of training the network during each training phase is chosen to be 10.000 .

The optimal architecture of MLP is found sustaining the approach that initially a small MLP is constructed and later additional inputs and units of a hidden layer are added until an appropriate solution is found (Muller et al., 1995). The optimal architecture of MLP is selected based on the analysis of the following measures:

- the selection subset performance is the highest;

- the selection and test errors of the neural network are low and close together. This gives some confidence that they reflect the expected generalization performance;

- the S. D. ratio is the ratio of the prediction error standard deviation to the original output data standard deviation. A lower S. D. ratio indicates a better prediction. 
- the mean absolute percentage error $\left(M A P E_{\text {test_subset }}\right)$ is an indicator of the MLP-based model accuracy. It is calculated by (7) and considering that $N$ is the number of observations in a test subset.

\section{Method of the Sensitivity Analysis}

Once the MLP-based model is constructed, the sensitivity analysis is performed. It is applied to identify and rate the key determinants of the electricity price expectations in the model. Two measures are considered: the ratio and the rank. The ratio is the basic measure. High ratio indicates an important input to the model. Based on the ratio, the rank is given. The rank indicates the ordering of the ratios. Rank 1 means that the input is the most relevant, rank 2 - the input is relevant, rank 3 - the input is less relevant to the model, etc.

\section{E. Method of the Forecast Accuracy Assessment}

The forecast accuracy of the MLP-based model is measured with data, which are not used in the subsets of training, selection and test of the model. This is a new subset consisting of 24 actual electricity prices, representing prices during a new day, which is not analysed during the process of model construction. The forecast accuracy is assessed by (7):

$$
M A P E=\frac{1}{N} \cdot \sum_{i=1}^{N} \frac{\left|P_{\mathrm{a}, i}-P_{\mathrm{e}, i}\right|}{\bar{P}} \cdot 100 \%,
$$

where MAPE is the mean absolute percentage error; $N$ is the number of observations $(N=24) ; P_{\mathrm{a}, i}$ is the actual electricity price during an hour $i ; P_{\mathrm{e}, i}$ is the expected (forecasted) electricity price during an hour $i ; \bar{P}$ is the average electricity price of 24 hours $(N=24)$.

If $M A P E$ is up to $10 \%$, then expectations (forecasts) are very accurate. Thus, the MLP-based model fits well in order to model the electricity price expectations. As MAPE increases, the accuracy of the MLP-based model reduces.

\section{F. Method for the Quantification of the Generator's Profit}

Forecasted electricity prices are used to take the electricity production decision. When quantifying the impact of the electricity production decision on the generator's profit during a new day ( $N=24$ hours), several questions are answered.

Firstly, is the generator ready to produce electricity subject to the forecasted (expected) price? The generator will take a decision to produce electricity during the specific hour $i$ if the marginal cost of electricity does not exceed the expected price of electricity, as it is represented by (8):

$$
D_{\mathrm{e}}(i)=\left\{\begin{array}{l}
1, P_{\mathrm{e}, i} \geq M C, \\
0, P_{\mathrm{e}, i}<M C,
\end{array}\right.
$$

where $D_{\mathrm{e}}(i)$ is the generator's decision to produce (1) or not (0) electricity during the specific hour $i, i=1,2, \ldots, 24 ; M C$ is the marginal cost of electricity; $P_{\mathrm{e}, i}$ is the expected electricity price during the hour $i$.
Secondly, what is the accuracy of the generator's decision in relation to electricity production? The accuracy of the generator's decision is calculated by (9):

$$
A=\frac{\sum_{i=1}^{24} M_{(\mathrm{e} / \mathrm{a}), i}}{24},
$$

where $M_{(\mathrm{e} / \mathrm{a}), i}$ is the match of a decision to produce electricity based on the expected $\left(P_{\mathrm{e}}\right)$ and actual $\left(P_{\mathrm{a}}\right)$ electricity prices.

The match of a decision to produce electricity based on $P_{\mathrm{e}}$ and $P_{\mathrm{a}}$ is quantified by (10):

$$
M_{(\mathrm{e} / \mathrm{a}), i}=\left\{\begin{array}{l}
1, D_{\mathrm{e}}(i)=D_{\mathrm{a}}(i), \\
0, \text { other, }
\end{array}\right.
$$

where $D_{\mathrm{a}}(i)$ is the decision of the generator to produce electricity during the specific hour based on the actual price $\left(P_{\mathrm{a}}\right)$ formed in the competitive electricity market. $D_{\mathrm{a}}(i)$ is assessed by (8), but instead of the expected electricity price $\left(P_{\mathrm{e}}\right)$ the actual electricity price $\left(P_{\mathrm{a}}\right)$ is used.

Thirdly, how much of electricity is generator going to produce during the specific hour? Technical parameters are important. However, for the simplicity reasons an assumption is taken that the generator is going to produce $1 \mathrm{MWh}$ of electricity during all types of the day and natural seasons.

Fourthly, what is the net impact of the production decision on the generator's profit? The net impact of the production decision is calculated by (11):

$$
\Delta \Pi=\sum_{i=1}^{24} \Pi_{\mathrm{e}, i}-\sum_{i=1}^{24} \Pi_{\mathrm{a}, i},
$$

where $\Pi_{\mathrm{e}, i}$ is the expected profit during the hour $i ; \Pi_{\mathrm{a}, i}$ is the actual profit during the hour $i$.

If $\Delta \Pi=0$, then electricity price expectations are confirmed and the generator actually earned the profit as expected. However, if $\Delta \Pi<0$, then the generator actually earned more profit than it was expected. This means that the expected price of electricity was undervalued by the generator and electricity price expectations were pessimistic. When the generator had optimistic expectations regarding the price development in future, then $\Delta \Pi>0$. This means that the generator actually earned less profit than it was expected.

The expected profit during the hour $i$ depends on the generator's decision $D_{\mathrm{e}}(i)$. If the generator takes a decision not to produce electricity, i.e., $D_{\mathrm{e}}(i)=0$, then the expected losses are limited to the fixed costs. However, if the generator decides to produce electricity, i.e., $D_{\mathrm{e}}(i)=1$, then the expected profit/loss is calculated by (12):

$$
\left\{\begin{array}{l}
\Pi_{\mathrm{e}, i}=T C_{\mathrm{e}, i}-T R_{\mathrm{e}, i}, \\
T C_{\mathrm{e}, i}=V C_{\mathrm{e}, i}+F C_{i}, \\
T R_{\mathrm{e}, i}=P_{\mathrm{e}, i} \cdot Q_{i},
\end{array}\right.
$$




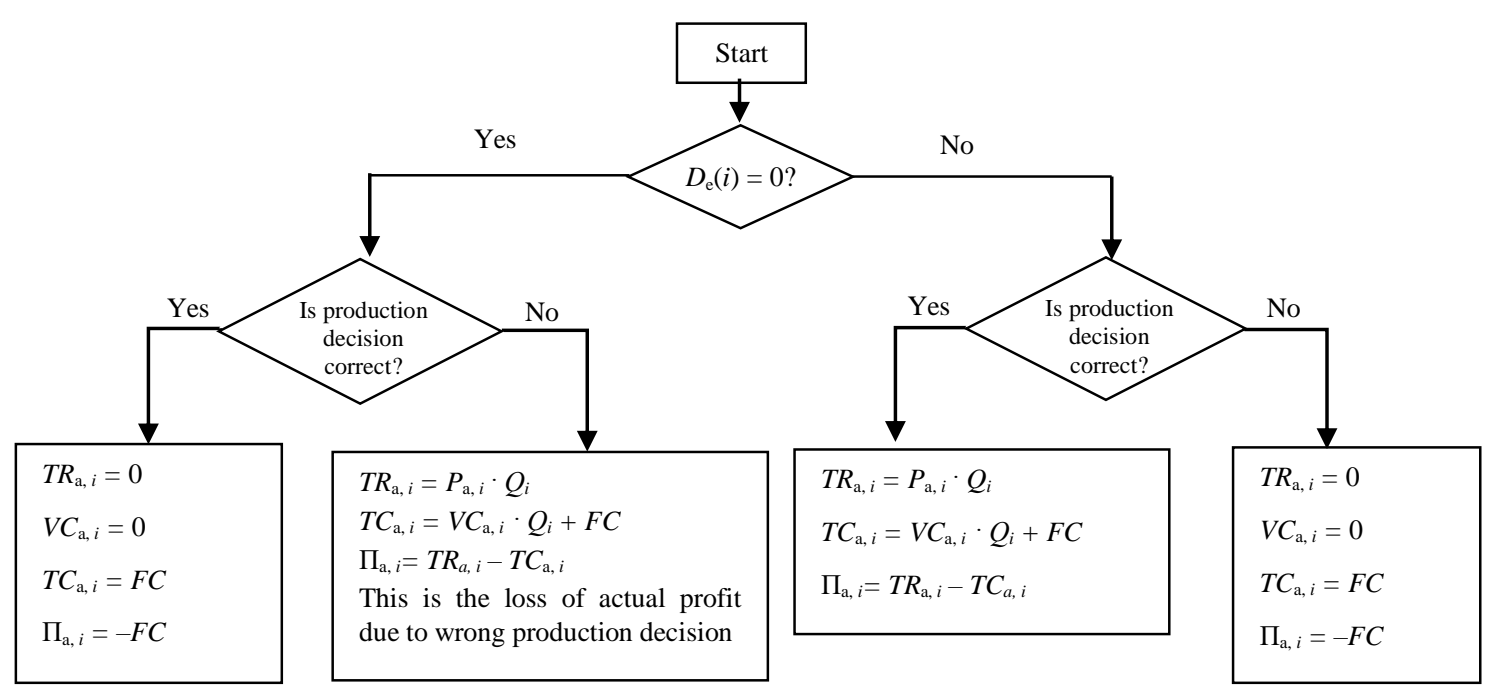

Fig. 2. Chart flow for calculation of the actual profit/loss, where $T C_{\mathrm{a}, i}$ is the actual total costs of electricity production during the hour $i$; $V C_{\mathrm{a}, i}$ is the actual variable costs during the hour $i ; T R_{\mathrm{a}, i}$ is the actual revenue during the hour $i ; P_{\mathrm{a}, i}$ is the actual electricity price during the hour $i$; $\Pi_{\mathrm{a}, i}$ is the actual profit/loss during the hour $i$.

where $T C_{\mathrm{e}, i}$ is the expected total costs of electricity production during the hour $i ; T R_{\mathrm{e}, i}$ is the expected revenue during the hour $i ; V C_{\mathrm{e}, i}$ is the expected variable costs during the hour $i ; F C_{i}$ is the fixed costs during the hour $i ; P_{\mathrm{e}, i}$ is the expected price during the hour $i ; Q_{i}$ is electricity production volume during the hour $i$.

The actual profit during the hour $i$ depends on the correctness of the production decision $D_{\mathrm{e}}(i)$. The chart flow for the calculation of actual profit / loss is presented in Fig. 2.

TABLE III

THE DETERMINANTS OF ELECTRICITY PRODUCTION COSTS AND THEIR VALUES (LITHUANIAN DISTRICT HEATING ASSOCIATION, 2013; KONSTANTINAVICIUTE \& BoBINAITE, 2015; EEX, 2016)

\begin{tabular}{|l|l|l|}
\hline Determinant & Units & Value \\
\hline Natural gas consumption & toe/MWh & 0.1135 \\
\hline Natural gas price & EUR/toe & 490.00 \\
\hline Costs of natural gas consumption & EUR/MWh & 55.62 \\
\hline Volume of $\mathrm{CO}_{2}$ emissions & tCO$_{2} / \mathrm{MWh}$ & 0.26 \\
\hline Price of $\mathrm{CO}_{2}$ emissions & EUR/tCO & 7.50 \\
\hline Costs of $\mathrm{CO}_{2}$ emissions & EUR/MWh & 1.95 \\
\hline Variable cost & EUR/MWh & 57.57 \\
\hline Fixed cost & EUR/MW per hour & 11.03 \\
\hline
\end{tabular}

The determinants of electricity production costs and their values are presented in Table III.

\section{RESULTS}

\section{A. Analysis of Electricity Price Development in Latvia}

The Latvian bidding area of the Scandinavian power exchange was launched on 3 June 2013. The establishment of a day-ahead market created a new background for electricity trading and transparent price setting. At present, electricity price in the Latvian day-ahead market is set on an hourly basis and is calculated based on the application of the social welfare criterion in combination with market rules (Nord Pool Spot, 2016). The application of new principals for price setting influences the display of additional features of electricity prices. These features are worth understanding when modelling electricity price expectations.

The Latvian electricity price profile shows a periodicity. These are seasonal, daily and hourly cycles (Figs. 3-4).

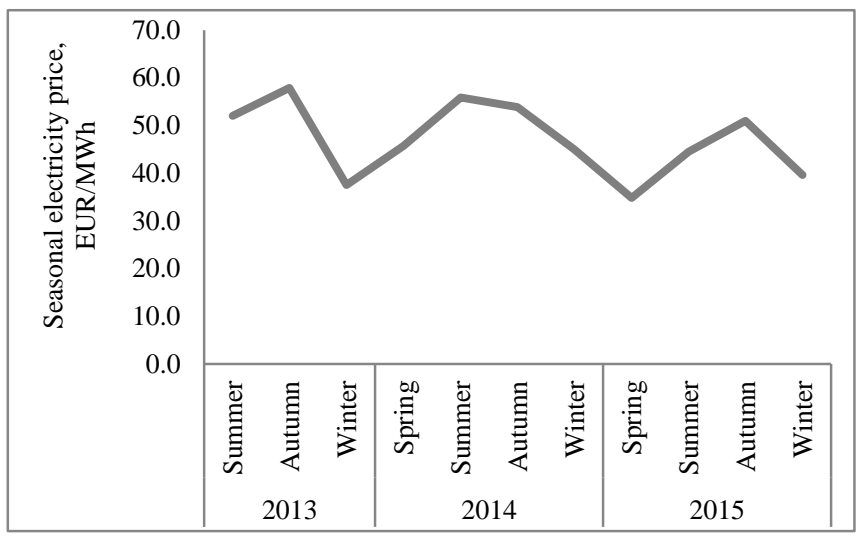

Fig. 3. Seasonal electricity price profile (Nord Pool Spot, 2016).

The seasonal electricity price profile (Fig. 3) demonstrates periodical electricity price development during the natural seasons. An average electricity price in summer and autumn is twice as high as in winter and spring. Mainly, this is related to the peculiarities of the operational regime of hydro and thermal power plants in the Baltic States, electricity consumption volumes and cross-border flows of electricity during the seasons. Climatic factors (temperature, wind and precipitations) also play an important role. Moreover, electricity prices in Latvia depend on the established situation in the Nordic Region and relations with other neighbouring countries. 


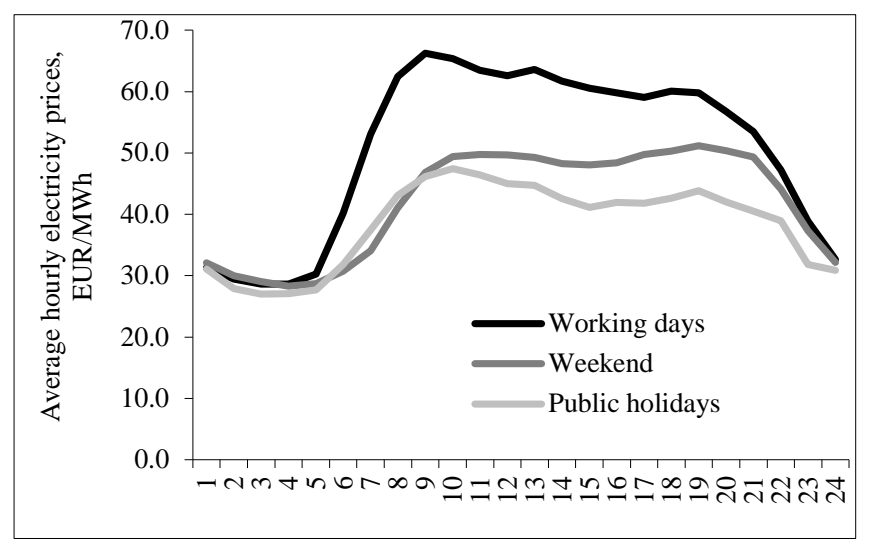

Fig. 4. Average hourly electricity price profiles (Nord Pool Spot, 2016).

The daily electricity price profile (Fig. 4), reflecting changes in the electricity market behaviour on working days, weekends and public holidays, shows that due to the living style of the Latvian society, the electricity price is considerably higher on Monday-Friday than on SaturdaySunday.

The price profile on public holidays is slightly different from non-holidays (Fig. 4). Electricity price in the morning and day-time on public holidays is by one-third lower than on working days, but its periodicity is approximate to these days, i.e., with a growing electricity consumption volume, price increases during the morning hours (6-9 a.m.) and achieves peak of 46 EUR/MWh at 9 a.m.; then has a small reducing (0.9\% per hour) tendency during the daytime (10 a.m. to 7 p.m.) and a deep reduction ( $9 \%$ per hour) during the evening hours $(8-11$ p.m.); subject to low electricity consumption volumes, at night electricity price is the lowest within a day - 28 EUR/MWh.

Figure 5 presents that electricity price is volatile in Latvia.

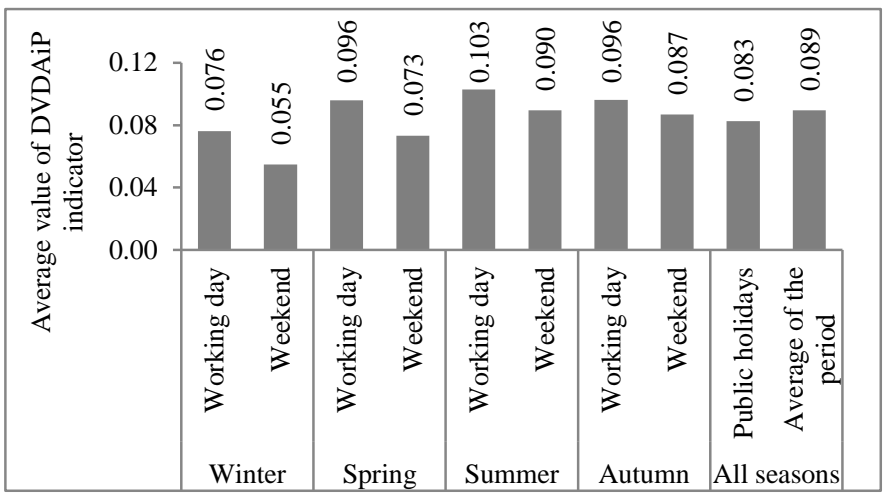

Fig. 5. The daily velocity, which is based on the daily average price, $\left(\mathrm{DVDA}_{\mathrm{iP}}\right)$ (calculated by the authors).

The development of the average $\mathrm{DVDA}_{\mathrm{iP}}$ indicator during the natural seasons and type of the day reveals that the average electricity price change has been about $8.9 \%$ of the average daily price. Price volatility increases in summer and autumn, but reduces in winter and spring. The most volatile electricity prices are on working days, but price volatility decreases on weekends and public holidays. For example, the average value of $\mathrm{DVDA}_{\mathrm{iP}}$ indicator is 0.055 on weekends in winter, but 0.103 - on working days in summer. This shows an average price change of $5.5 \%$ and $10.3 \%$ of the average daily price, respectively.

Figure 6 presents information about electricity price spikes.

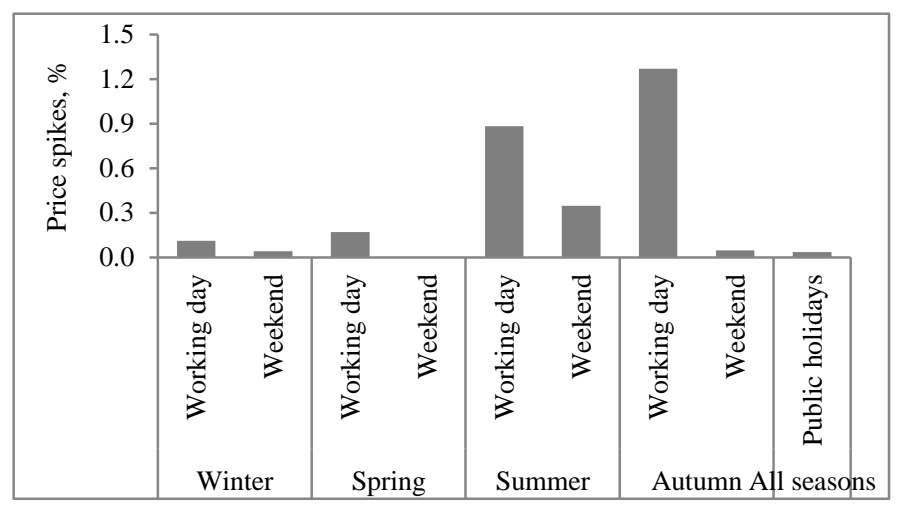

Fig. 6. Electricity price spikes in the Latvian day-ahead market (calculated by the authors).

Electricity price is spiking in Latvia. All prices that are below 6.26 EUR/MWh and higher than 89.33 EUR/MWh are considered to be price spikes. In Latvia, price spikes mean very high prices. They were present for $2.92 \%$ of the time span under consideration. Very low prices were absent in Latvia. Price spikes usually form in summer and autumn, encompassing $1.23 \%$ and $1.32 \%$ of time, respectively. Usually they are on working days, most likely as a result of increased demand of electricity. In winter and spring price spikes form less frequently.

Due to differences in the features of electricity prices during the natural seasons and the types of the day, it is decided to prepare separate models of electricity price expectations for different natural seasons and types of the day. Clustering the days to the groups is important since this improves the accuracy of the models of price expectations, as it was observed by V. Vahidinasab et al. (2008).

\section{B. Models of the Electricity Price Expectations}

80 models for each natural season (40 - for working days and 40 - for weekends) and 40 models for public holidays are constructed. In total, 400 models are prepared. They differ in a number of inputs and units of a hidden layer. The initial analysis of the models shows that they do not differ significantly in a selection subset performance, selection and test errors, S. D. ratios and the coefficients of determination; therefore, one model for each natural season and type of the day is selected. The characteristic of the model is its compact and as simple as possible MLP architecture. The summary of the selected models is presented in Table IV. 
TABLE IV

Parameters of THE Models of EleCtricity Price EXPECTATIONS (CALCUlations Made By THE Authors)

\begin{tabular}{|l|l|l|l|l|l|l|l|l|l|}
\hline $\begin{array}{l}\text { No. of } \\
\text { the } \\
\text { model }\end{array}$ & $\begin{array}{l}\text { Natural } \\
\text { season }\end{array}$ & Type of day & Model description* & $\begin{array}{l}\text { Selection } \\
\text { subset } \\
\text { performance }\end{array}$ & $\begin{array}{l}\text { S.D. } \\
\text { ratio }\end{array}$ & $\begin{array}{l}\text { Coefficient of } \\
\text { determination }\end{array}$ & $\begin{array}{l}\text { Selection } \\
\text { error }\end{array}$ & $\begin{array}{l}\text { Test } \\
\text { error }\end{array}$ & MAPE \\
\hline 1 & Autumn & Working days & MLP $8: 5: 1$ (autumset & 0.63 & 0.61 & 0.63 & 0.08 & 0.08 & 14.93 \\
\hline 2 & Autumn & Weekends & MLP $6: 4: 1$ & 0.71 & 0.72 & 0.48 & 0.06 & 0.05 & 16.38 \\
\hline 3 & Winter & Working days & MLP $4: 6: 1$ & 0.69 & 0.66 & 0.57 & 0.07 & 0.07 & 13.84 \\
\hline 4 & Winter & Weekends & MLP 7 $: 4: 1$ & 0.82 & 0.81 & 0.35 & 0.06 & 0.06 & 16.83 \\
\hline 5 & Spring & Working days & MLP $6: 5: 1$ & 0.65 & 0.65 & 0.58 & 0.04 & 0.04 & 14.63 \\
\hline 6 & Spring & Weekends & MLP $6: 6: 1$ & 0.69 & 0.69 & 0.53 & 0.15 & 0.14 & 16.12 \\
\hline 7 & Summer & Working days & $\begin{array}{l}\text { MLP } 8: 5: 1 \\
\text { (summer) }\end{array}$ & 0.53 & 0.55 & 0.69 & 0.05 & 0.06 & 14.13 \\
\hline 8 & Summer & Weekends & MLP 4 $: 7: 1$ & 0.68 & 0.73 & 0.47 & 0.07 & 0.08 & 20.85 \\
\hline 9 & All seasons & Public holidays & MLP 4 $: 5: 1$ & 0.68 & 0.58 & 0.67 & 0.15 & 0.14 & 19.15 \\
\hline
\end{tabular}

$*<$ Network type $><$ Number of inputs $>:<$ Units in the hidden layer $>:<$ Number of outputs $>$

Results presented in Table IV demonstrate that electricity price expectations could be measured using the multifactor MLP-based models, which assess 4-8 determinants. The determinants explain up to $70 \%$ of the variance of electricity prices, as the coefficients of determination show.

The models for working days and public holidays are of better quality compared to those for weekends, when the coefficient of determination is considered. The selected determinants explain only $35 \%$ to $53 \%$ of the variance of electricity prices on weekends, while $57 \%$ to $69 \%$ - on working days and $67 \%$ - on public holidays. Thus, the power of other determinants explaining the price development remains significant, especially on weekends.

The accuracy of the models is good, since $M A P E \mathrm{~s}_{\text {test subset }}$ do not exceed $20 \%$, except in the case of the MLP 4:7:1 model, which analyses prices on weekends in summer. Its accuracy is moderate, since $M A P E_{\text {test subset }}$ is $20.85 \%$. As MAPEs test subset do not exceed $50 \%$ (Bartosevičienè, 2001), the models are sufficient to be used to model electricity price expectations.

The MLP-based models capture volatility of prices and price spikes, as Fig. 7 shows. Low volatile and slightly spiking electricity prices in winter and spring are related to good accuracy of the models, i.e., MAPE $E_{\text {test subset }}$ of MLP $4: 6: 1$, MLP $7: 4: 1$, MLP $6: 5: 1$ and MLP $6: 6: 1$ vary in the range of $13.84 \%$ to $16.83 \%$. Although volatility increases and prices start spiking in summer and autumn, the models capture the features and the accuracy of models (MLP $8: 5: 1$ (summer), MLP $8: 5: 1$ (autumn) and MLP $6: 4: 1$ ) is kept at a good rate $\left(M A P E_{\text {test subset }}=14.13 \%\right.$ to $\left.16.38 \%\right)$. Only in case of the model MLP $4: 7: 1$, an increased volatility and spiking prices are captured at a moderate rate of accuracy $\left(M A P E_{\text {test subset }}=20.85 \%\right)$.

The MLP $4: 7: 1, \quad$ MLP $6: 4: 1, \quad$ MLP $7: 4: 1$, MLP 6:6:1 models consider prices on weekends and MLP $4: 5: 1$ - on public holidays. The accuracy of these models is slightly lower compared to models for working days. The history of prices on weekends and public holidays is shorter; therefore, this is likely a reason for the selected functions to approximate the price features at a lower rate of accuracy. Considering the results of models for working days, it is expected that with an increased amount of historical data, the models for weekends and public holidays will achieve a higher level of approximation.

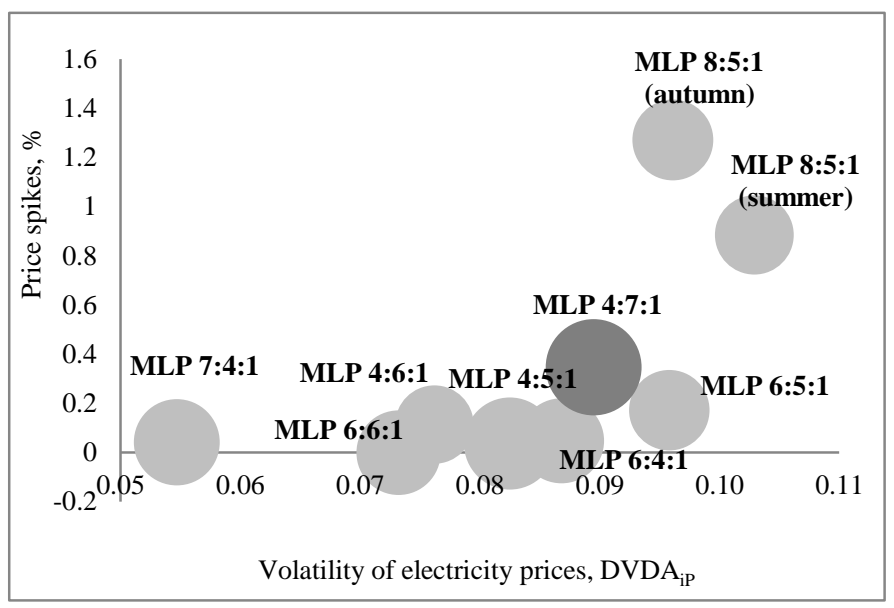

The size of the burble shows $M A P E_{\text {test_subset; }}$, the larger the bubble, the higher $M A P E_{\text {test__subset. }}$

Fig. 7. The relationship between volatility, price spikes and accuracy of the models (made by the authors).

Thus, the theory of adaptive price expectations and the neural network approach could be applied to model electricity price expectations. The accuracy of models is found to be good in almost all cases, but it is slightly reduced in models, which analyse prices on weekends. Thus, it is necessary to continue searching for ways how to improve the latter models, including the study of additional determinants of price expectations, testing the theory of rational expectations and applying the advanced input selection algorithms. However, at this stage, the authors assess how valuable the theory of adaptive expectations is when modelling price expectations. 
TABLE V

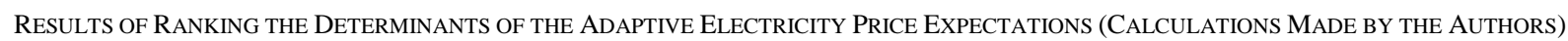

\begin{tabular}{|l|l|l|l|l|l|l|l|l|l|}
\hline $\begin{array}{l}\text { No of the } \\
\text { model }\end{array}$ & Model description & $\boldsymbol{P}_{t-24}$ & $\boldsymbol{P}_{t-48}$ & $\boldsymbol{P}_{t-72}$ & $\boldsymbol{P}_{t-96}$ & $\boldsymbol{P}_{t-120}$ & $\boldsymbol{P}_{t-240}$ & $\boldsymbol{P}_{t-360}$ & $\boldsymbol{P}_{t-480}$ \\
\hline 1 & MLP 8 $: 5: 1$ (autumn) & 1 & 2 & 4 & 7 & 8 & 3 & 5 & 6 \\
\hline 2 & MLP 6 $: 4: 1$ & 1 & 2 & 6 & 5 & 3 & 4 & - & - \\
\hline 3 & MLP 4 $6: 1$ & 1 & 4 & 2 & 3 & - & - & - & - \\
\hline 4 & MLP 7 $: 4: 1$ & 1 & 3 & 4 & 2 & - & 6 & 5 & 7 \\
\hline 5 & MLP 6 $: 5: 1$ & 1 & 5 & 6 & 4 & 2 & 3 & - & - \\
\hline 6 & MLP 6 $: 6: 1$ & 4 & 6 & 3 & 5 & 2 & 1 & - & - \\
\hline 7 & MLP 8 : 5:1 (summer) & 1 & 2 & 3 & 4 & 7 & 8 & 6 & 5 \\
\hline 8 & MLP 4 $: 7: 1$ & 1 & 2 & - & - & - & 4 & - & 3 \\
\hline 9 & MLP 4 : 5:1 & 4 & 3 & 1 & 2 & - & - & - & - \\
\hline
\end{tabular}

\section{Results of the Sensitivity Analysis}

Table $\mathrm{V}$ presents the key determinants of the adaptive electricity price expectations.

As it is shown in Table $\mathrm{V}$, the electricity price expectations depend on the history of the electricity prices, which seeks 480 hours backwards.

The long history of the electricity prices (up to 480 hours backwards) is used to model price expectations during volatile and spiking periods, i.e., on the working days in autumn and both on working days and weekends in summer.

As the price volatility and the amount of price spikes reduce, the relevance of the past prices in the particular model also reduces. The medium-term (up to 240 hours backwards) electricity price information is used on weekends in autumn and both on weekends and working days in spring.

The electricity price expectations on public holidays and working days in winter are modelled based on the short-term (up to 96 hours backwards) price data.

Notwithstanding the type of the day and natural season, the electricity price expectations depend mostly on the electricity price a day before $\left(P_{t-24}\right)$. The importance of price information reduces as time looking to the past lengthens, as the models MLP $8: 5: 1$ (autumn), MLP $7: 4: 1$ and MLP $8: 5: 1$ (summer) show.

Thus, the results of sensitivity analysis are important for the electricity generator in a sense they provide information about the past prices that have to be considered when modelling electricity price expectations during the natural seasons and type of the day.

\section{Electricity Price Expectations and Their Accuracy}

The electricity price expectations are modelled by using additional 24 prices in the constructed models. The features of prices and their comparison are presented in Table VI.

As it is shown in Table VI, prices, which are included in the datasets used to forecast prices, are not spiking. This is an extenuating condition of modelling electricity price expectations.
TABLE VI

The FEATURES OF ELECTRICITY PRICES IN DIFFERENT DATASETS (CALCUlations MADE BY AUTHORS)

\begin{tabular}{|l|l|l|l|l|l|}
\hline \multirow{2}{*}{$\begin{array}{l}\text { No. of } \\
\text { the } \\
\text { model }\end{array}$} & \multirow{2}{*}{$\begin{array}{l}\text { Model } \\
\text { description }\end{array}$} & $\begin{array}{l}\text { Price volatility } \\
\text { used to } \\
\text { construct } \\
\text { the model }\end{array}$ & $\begin{array}{l}\text { Dataset } \\
\text { used to } \\
\text { forecast } \\
\text { prices }\end{array}$ & $\begin{array}{l}\text { Pataset } \\
\text { used to } \\
\text { construct } \\
\text { the } \\
\text { model }\end{array}$ & $\begin{array}{l}\text { Dataset } \\
\text { used to } \\
\text { forecast } \\
\text { prices }\end{array}$ \\
\hline 1 & $\begin{array}{l}\text { MLP 8 }: 5: 1 \\
\text { (autumn) }\end{array}$ & 0.0961 & 0.0703 & 1.27 & 0.00 \\
\hline 2 & MLP 6 : 4:1 & 0.0868 & 0.1025 & 0.05 & 0.00 \\
\hline 3 & MLP 4 : 6:1 & 0.0762 & 0.1104 & 0.11 & 0.00 \\
\hline 4 & MLP 7 : 4:1 & 0.0547 & 0.1035 & 0.04 & 0.00 \\
\hline 5 & MLP 6 : 5:1 & 0.0958 & 0.0871 & 0.17 & 0.00 \\
\hline 6 & MLP 6 : 6:1 & 0.0732 & 0.1524 & 0.00 & 0.00 \\
\hline 7 & $\begin{array}{l}\text { MLP 8 : 5:1 } \\
\text { (summer) }\end{array}$ & 0.1029 & 0.0646 & 0.89 & 0.00 \\
\hline 8 & MLP 4 : 7:1 & 0.0895 & 0.0587 & 0.35 & 0.00 \\
\hline 9 & MLP 4 : 5:1 & 0.0894 & 0.0870 & 0.04 & 0.00 \\
\hline
\end{tabular}

Besides, prices in a dataset used to forecast prices are less volatile when a working day of a particular season is considered. Thus, it is expected that the accuracy of price expectations on working days will be very high (MAPE is less than $10 \%$ ) or good (MAPE is $10 \%$ to $20 \%$ ).

However, price volatility significantly increases on weekends. For example, prices in the datasets used to forecast prices on weekend in spring and winter are twice volatile as they are in the datasets used to construct the MLP $6: 6: 1$ and MLP $7: 4: 1$ models. Therefore, it is expected that due to significantly increased volatility, the accuracy of price expectations will reduce on weekends.

The accuracy of electricity price expectations is presented in Fig. 8. 


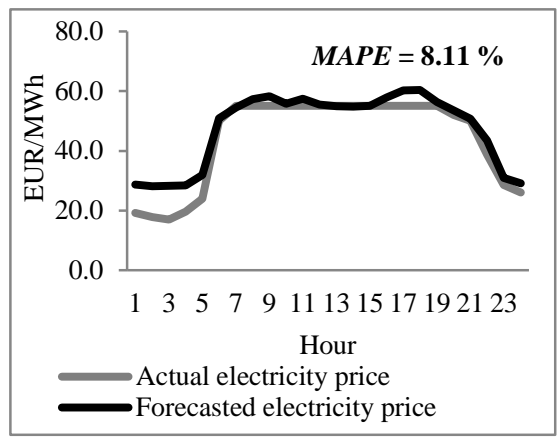

a) MLP $8: 5: 1$ (autumn)

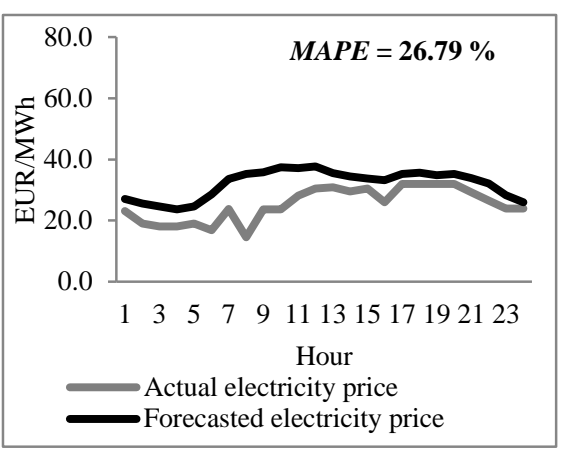

d) MLP $7: 4: 1$

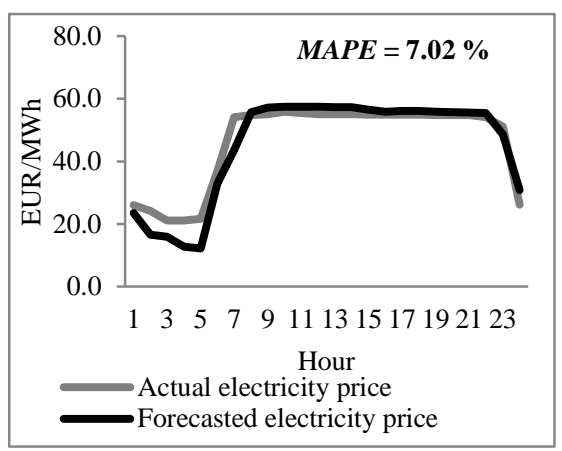

g) MLP $8: 5: 1$ (summer)

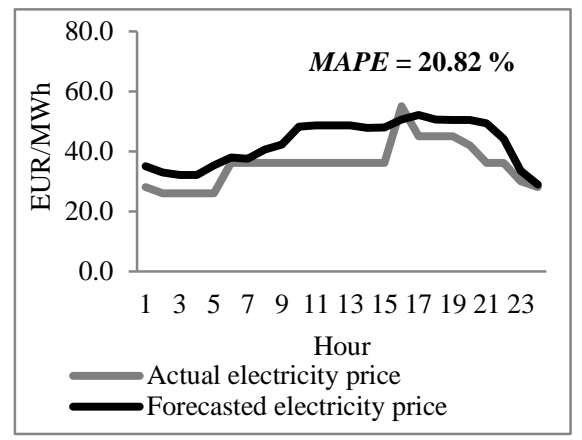

b) MLP $6: 4: 1$

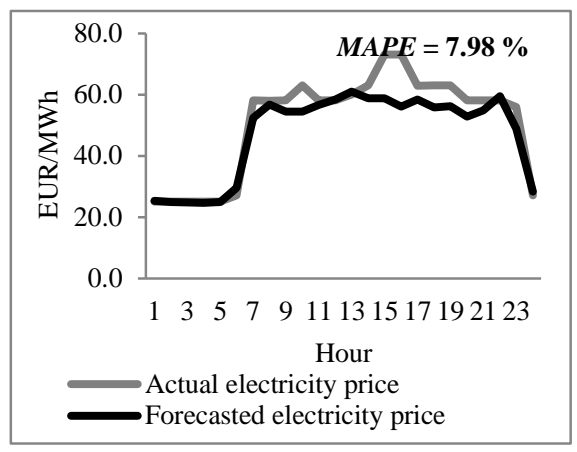

e) MLP $6: 5: 1$

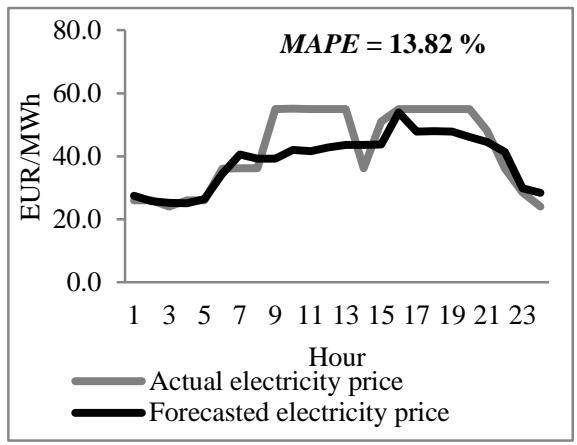

h) MLP $4: 7: 1$

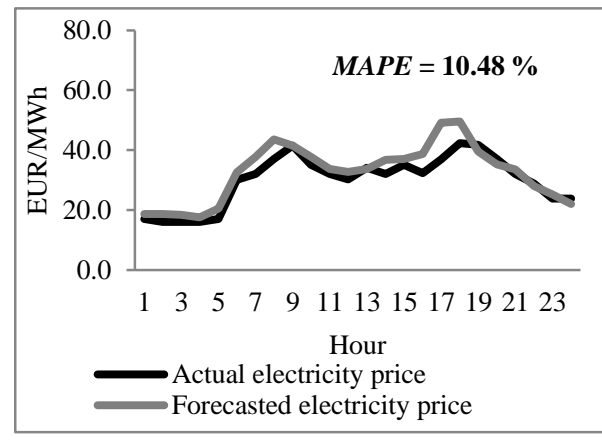

c) MLP $4: 6: 1$

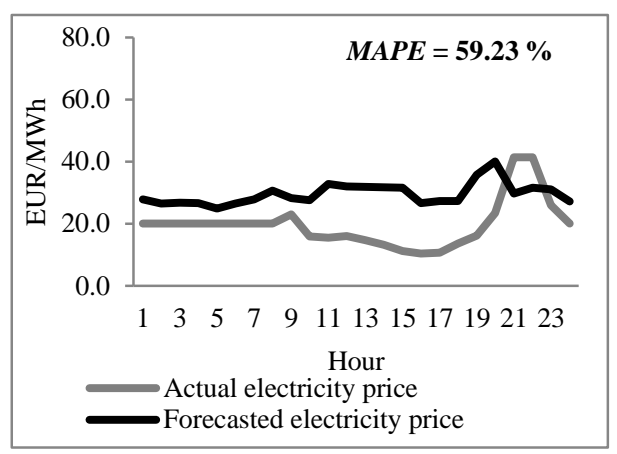

f) MLP $6: 6: 1$

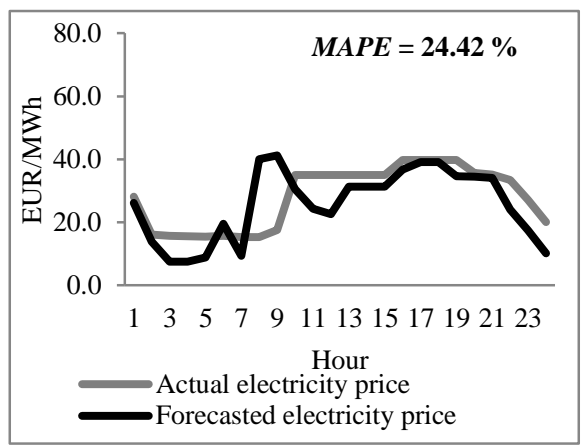

i) MLP $4: 5: 1$

Fig. 8. Actual and forecasted (expected) electricity prices and the accuracy of the predictions subject to different models (calculations made by the authors).

As it is shown in Fig. 8, the accuracy of price expectations differs. The electricity price expectations are found to be the most accurate on working days (MLP $8: 5: 1$ (autumn), MLP $6: 5: 1$, MLP $8: 5: 1$ (summer) and MLP $4: 6: 1$ ). MAPEs vary in the range of $7.02 \%$ to $10.48 \%$. The accuracy of price expectations on weekends and public holidays are worse and $M A P E$ s vary in the range of $13.82 \%$ to $59.23 \%$. In addition to what has been said in the Section above, it could be added that the accuracy reduces due to the profile of 24 actual electricity prices, i.e., it relevantly differs from the average profile (Fig. 4), which is considered to construct the model. Thus, this shows that the power of the models to measure the adaptive price expectations on weekends accurately should be improved by including additional determinants of price expectations into the models.
The comparison of the accuracy of electricity price expectations found in the scientific literature with our own results is given in Table VII.

The research results presented in the paper and Table VII are similar to findings of A. J. Conejo et al. (2005) and P. Dev \& M. A. Martin (2014) who found that in time of volatile prices, when the price profile changes, the MAPEs could increase up to $30 \%$, and up to $130 \%$, when prices start spiking. More precisely, P. Dev \& M. A. Martin (2014) state that the neural network-based models are acceptable for capturing the general features of prices, except for inability to capture price spikes adequately, i.e., they can capture the time of price spike but not the size of a spike. Besides, they found that much of volatility in prices cannot be adequately explained by historical prices. 
TABLE VII

COMPARISON OF MAPES OF OUR OWN AND OTHER SCIENTISTS' COMPUTATIONS

\begin{tabular}{|c|c|c|c|c|c|c|c|c|c|}
\hline $\begin{array}{l}\text { Natural } \\
\text { season }\end{array}$ & Type of day & $\begin{array}{l}\text { Our own } \\
\text { work }\end{array}$ & $\begin{array}{l}\text { A. J. Conejo } \\
\text { et al. (2005) }\end{array}$ & $\begin{array}{l}\text { J.P. S. } \\
\text { Catalão } \\
\text { et al. } \\
(2007)\end{array}$ & $\begin{array}{l}\text { N. Amjady \& } \\
\text { F. Keynia } \\
\text { (2009) }\end{array}$ & $\begin{array}{l}\text { W.-M. } \\
\text { Lin } \text { et al. } \\
\text { (2010) }\end{array}$ & $\begin{array}{l}\text { S. Anbazhagan \& } \\
\text { N. Kumarappan } \\
\text { (2014) }\end{array}$ & $\begin{array}{l}\text { P. Dev \& M. } \\
\text { A. Martin } \\
\text { (2014) }\end{array}$ & $\begin{array}{l}\text { M. Al- } \\
\text { Shakhs \& } \\
\text { M. El- } \\
\text { Hawary } \\
\text { (2015) }\end{array}$ \\
\hline Autumn & $\begin{array}{l}\text { Working } \\
\text { days }\end{array}$ & 8.11 & $6.45-16.81$ & \multirow[t]{2}{*}{13.65} & \multirow[t]{2}{*}{$6.20-10.65$} & - & \multirow[t]{2}{*}{8.65} & \multirow{9}{*}{$\begin{array}{l}24.4-132.5 \\
\text { (working days) } \\
22.7-55.1 \\
\text { (weekends) } \\
\text { Victorian } \\
\text { region, } \\
\text { Australia }\end{array}$} & - \\
\hline Autumn & Weekends & 20.82 & $9.06-17.70$ & & & $8.2-48.9$ & & & - \\
\hline Winter & $\begin{array}{l}\text { Working } \\
\text { days }\end{array}$ & 10.48 & $6.08-14.07$ & \multirow[t]{2}{*}{5.23} & \multirow[t]{2}{*}{$4.32-7.11$} & - & \multirow[t]{2}{*}{4.03} & & - \\
\hline Winter & Weekends & 26.79 & $6.10-6.82$ & & & - & & & - \\
\hline Spring & $\begin{array}{l}\text { Working } \\
\text { days }\end{array}$ & 7.98 & $6.42-15.38$ & \multirow[t]{2}{*}{5.36} & \multirow[t]{2}{*}{$4.31-6.98$} & $7.6-23.8$ & \multirow[t]{2}{*}{4.29} & & \multirow[t]{2}{*}{$6.45-8.77$} \\
\hline Spring & Weekends & 59.23 & $20.39-29.14$ & & & - & & & \\
\hline Summer & $\begin{array}{l}\text { Working } \\
\text { days }\end{array}$ & 7.02 & 7.99-28.38 & \multirow[t]{2}{*}{11.40} & \multirow[t]{2}{*}{$6.37-11.23$} & - & \multirow[t]{2}{*}{8.29} & & \multirow[t]{2}{*}{$6.12-9.14$} \\
\hline Summer & Weekends & 13.82 & $13.30-15.52$ & & & $5.4-34.1$ & & & \\
\hline $\begin{array}{l}\text { All } \\
\text { seasons }\end{array}$ & $\begin{array}{l}\text { Public } \\
\text { holidays }\end{array}$ & 24.42 & - & - & - & - & - & & - \\
\hline
\end{tabular}

This is the issue the authors of this paper met in their research, too. Thus, it is necessary to find out the explanatory power of other determinants of price expectations. However, it is worth noting that an inclusion of additional determinants, such as demand of electricity, does not necessarily improve the accuracy significantly (P. Dev \& M. A. Martin, 2014). Similar results were achieved by W.-M. Lin et al. (2010), who forecasted electricity prices by including loads, transfer flows and temperature. They found that very high MAPEs can be received when including other determinants than prices. Seeking to increase the forecast accuracy, W.-M. Lin et al. (2010) offered an enhanced probability neural network (EPNN), which integrates probability neural network (PNN) and orthogonal experimental design (OED). The latter helps improve the forecasts by the appropriate regulation of smoothing parameters. EPNN captures spikes accurately and has a capability to produce good results in case of volatile prices. The forecast accuracy of EPNN models is very high (MAPEs are $5.4 \%$ to $8.2 \%$ ), but it is satisfactory of PNN models (MAPEs are $23.8 \%$ to $48.9 \%$ ).

M. Al-Shakhs \& M. El-Hawary (2015) found that although the issue of modelling the price volatility cannot be solved entirely, various "innovations" applied in neural networks could contribute to the significantly improved accuracy of the forecasts. It was measured that, in a case an "exact innovation" to neural network is applied, 33.05\% improvement in forecast accuracy is achieved in summer and $26.41 \%$ - in spring.

N. Amjady \& F. Keynia (2009) disclosed the relevance of input selection techniques to the forecast accuracy. The scientists found that a two-stage feature selection technique, consisting of the modified Relief score algorithm and the cross-correlation analysis, is superior to one- and two-dimensional correlation analysis because it ensures lower MAPEs $(4.31 \%$ to $6.37 \%)$. The MAPEs of correlation analysis is $5.76 \%$ to $11.23 \%$. Thus, the advantage of a twostage feature selection algorithm could be exploited in future research seeking to increase the forecast accuracy, especially on weekends.

Furthermore, P. Dev \& M. A. Martin (2014) found that training the neural network with a larger dataset does not guarantee better accuracy.

When modelling price expectations with neural networks, issues arise; however, the approach remains a powerful tool to model electricity price developments. The results received by J. P. S Catalão et al. (2007) confirmed a considerable value of a neural network approach when forecasting electricity prices. Scientists observed that the neural networks outperform the time series methods, such as ARIMA. In case a neural network approach is applied, the forecast accuracy improves up to two times.

Thus, the research results presented in this paper can be inserted into the list of scientific papers dealing with the issue of modelling short-term electricity price expectations. It can be observed that the forecast accuracies obtained by the authors of this paper in many cases fall into the ranges of results presented by other scientists. However, there is a need to improve forecast accuracy of models for weekends by applying the methodological advantages of other studies.

\section{E. Microeconomic Implications}

If price expectations are formed considering the forecasted prices and the production decisions for the following 24 hours are taken based on the expected prices, then the accuracy of the production decision is the same as it is presented in Table VIII. 
TABLE VIII

ASSESSMENT OF THE ACCURACY OF THE PRODUCTION DECISION (CALCUlations MAde By tHE Authors)

\begin{tabular}{|l|l|l|}
\hline $\begin{array}{l}\text { No. of the } \\
\text { model }\end{array}$ & Model description & $\begin{array}{l}\text { The accuracy of the } \\
\text { production decision }(\boldsymbol{A})\end{array}$ \\
\hline 1 & MLP $8: 5: 1$ (autumn) & 0.83 \\
\hline 2 & MLP $6: 4: 1$ & 1.00 \\
\hline 3 & MLP $4: 6: 1$ & 1.00 \\
\hline 4 & MLP $7: 4: 1$ & 1.00 \\
\hline 5 & MLP $6: 5: 1$ & 0.58 \\
\hline 6 & MLP $6: 6: 1$ & 1.00 \\
\hline 7 & $\begin{array}{l}\text { MLP } 8: 5: 1 \\
\text { (summer) }\end{array}$ & 1.00 \\
\hline 8 & MLP $4: 7: 1$ & 1.00 \\
\hline 9 & MLP $4: 5: 1$ & 1.00 \\
\hline
\end{tabular}

Table VIII shows that the electricity generator's decisions in relation to the production schedule during the following 24 hours were correct on weekends and working days in winter (MLP $4: 6: 1$ and MLP $7: 4: 1$ ) and summer (MLP $8: 5: 1$ (summer) and MLP $4: 7: 1$ ) as well on weekends in autumn (MLP $6: 4: 1$ ) and spring (MLP $6: 6: 1$ ). The accuracy of the production decision is quantified as 1.00 . Actually, these are decisions "do not produce electricity", because of low expected electricity prices, which do not cover variable cost.

However, during some hours on a working day in spring (MLP 6:5:1) and autumn (MLP $8: 5: 1$ (autumn)) the electricity price expectations were not confirmed and the production decisions were also wrong. The inaccuracies of the decisions are quantified as $0.42(1.00-0.58)$ and $0.17(1.00-$ $0.83)$, respectively. This means $42 \%$ and $17 \%$ of hours on a working day in spring and autumn the generator's production decisions were incorrect. Actually, the generator's price expectations were optimistic on a working day in autumn, but pessimistic on a working day in spring.

The impact of price expectations on the profit/loss is presented in Fig. 9.

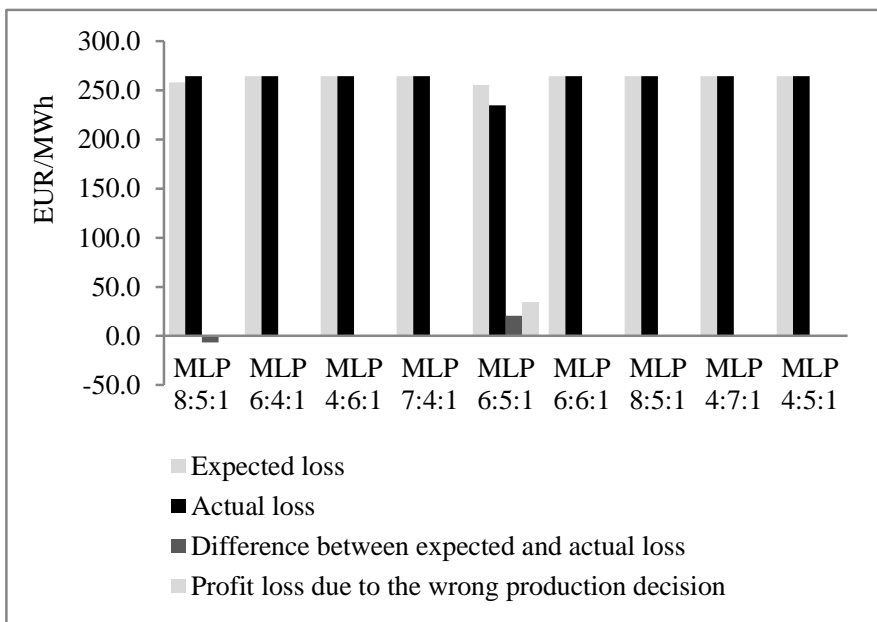

Fig. 9. The impact of electricity price expectations on the profit/loss of the electricity production during 24 hours (calculations made by the authors).
The results of the models MLP $6: 4: 1$, MLP $4: 6: 1$, MLP $7: 4: 1$, MLP $6: 6: 1$, MLP $8: 5: 1$ (summer), MLP $4: 7: 1$, MLP $4: 5: 1$ present the case, when the generator took the decisions "do not produce electricity" and the decisions were correct for all 24 hours. Thus, only the fixed costs were suffered-264.72 EUR - and both the actual and expected losses were limited to the fixed costs.

The results of the model MLP $8: 5: 1$ (autumn) show the impact of the optimistic price expectations on the losses. The generator expected to suffer losses of 258.32 EUR, but actually the incurred losses were 264.72 EUR. The difference between the actual and expected losses appeared because of the decisions "to produce and bid electricity" during some hours of the day, when the decisions were not accepted by the market and the generator could not sell electricity.

The results of the model MLP $6: 5: 1$ show that the generator expected to suffer losses of 255.44 EUR. However, the electricity price expectations were pessimistic and, as a result, the actual losses were by 20.44 EUR lower. During 7 to $11,16,18$ to 21 hours the generator could sell electricity on the market; however, he took the decisions "do not produce". The production decisions were wrong and he lost 34.71 EUR.

\section{CONCLUSION}

The research investigated the scientific issue of price expectations in the day-ahead electricity market in Latvia during 3 June 2013 to 9 February 2016. An integrated approach, which combines the fundamentals of the electricity prices, the electricity price forecasting method, the decision making and the results of the performance, to the electricity price expectations in a short-term has been developed.

The research results substantiate the significance of the adaptive expectations to analyse the formation of price expectations in the electricity market and demonstrate that electricity price expectations depend on the historical electricity prices. Namely, the generator forms price expectations considering to electricity prices up to 480 hours backwards.

The results of sensitivity analysis show that the electricity price a day ago is the most important determinant of the electricity price expectations and the relevance of prices behind to the past reduces.

The modelling results confirm the importance of the method of the neural network to model electricity price expectations in the short term. Nine MLP-based models of electricity price expectations have been developed. Their forecast accuracy differs from high to low depending on the natural season and type of the day. Errors of the forecasts vary in the range of $7.02 \%$ to $59.23 \%$ and leave a room for further research searching additional methodological solutions to improve the forecast accuracy, especially on weekends.

The comparison of research results with the results of other scientists shows that the forecast accuracies obtained by the authors of this paper in many cases fall into the ranges of results presented by other scientists. However, there is a need to improve forecast accuracy of models for weekends by applying the methodological advantages of other studies. 
Namely, it is essential to study additional determinants of price expectations, test the theory of rational expectations and apply the advanced input selection algorithms in future research.

The research results show that electricity price expectations affect the electricity production schedule, i.e., the generator's decision to produce electricity during certain hours of the day. The accuracy of production decision is found to be high on weekends and public holidays during all natural seasons; as well on working days in winter and summer. The accuracy of the production decisions is quantified as 1.00. The generator's production decisions are incorrect $42 \%$ and $17 \%$ of hours on working days in spring and autumn, respectively.

The results of profit/loss computation show that price expectations and followed production decisions for the next 24 hours affect the profit/loss of the generator. In case the accuracy of the production decisions is 1.00 , the electricity price expectations are confirmed and the actual and expected losses of the electricity generator are limited to the fixed costs -264.72 EUR. Due to the optimistic electricity price expectations on working days in autumn, the actual costs are by 6.4 EUR higher than it is expected. The pessimistic electricity price expectations on working days in spring affect actual costs decreasing them by 20.44 EUR; however, during some hours of the day the generator loss is 34.71 EUR. This is due to the production decisions "do not produce electricity", when there is a possibility to sell electricity in the market.

\section{ACKNOWLEDGEMENT}

The research has been supported by the Latvian State Education Development Agency; Scholarship grant No 15$16 / 20$.

\section{REFERENCES}

Abedinia, O., Amjady, N., Shafie-khah, M. \& Catalão J. P. S. (2015) Electricity price forecast using Combinatorial Neural Network trained by a new stochastic search method. Energy Conversion and Management, 105, 642-654. http://dx.doi.org/10.1016/j.enconman.2015.08.025

Aggarwal, S. K., Saini, L. M. \& Kumar, A. (2009). Electricity price forecasting in deregulated markets: A review and evaluation. International Journal of Electrical Power \& Energy Systems, 31(1), 1322. http://dx.doi.org/10.1016/j.ijepes.2008.09.003

Al-Shakhs, M. \& El-Hawary, M. (2015). Innovations-based Neural Network Seasonal Day-ahead Marginal Price Forecasting. Electric Power Components and Systems, 43(5), 588-593.

http://dx.doi.org/10.1080/15325008.2014.995279

Amjady, N. \& Keynia, F. (2009). Day-ahead price forecasting of electricity markets by a new feature selection algorithm and cascaded neural network technique. Energy Conversion and Management, 50(12), 29762982. http://dx.doi.org/10.1016/j.enconman.2009.07.016

Anbazhagan, S. \& Kumarappan, N. (2014). Day-ahead deregulated electricity market price forecasting using neural network input featured by DCT. Energy Conversion and Management, 78, 711-719. http://dx.doi.org/10.1016/j.enconman.2013.11.031

Anderson, D. R., Sweeney, D. J., Williams, T., Camm, J. D. \& Martin, K. (2009). Quantitative Methods for Business. South-Western Cengage Learning.

Armstrong, J. S. \& Green, K. C. (2010). Demand Forecasting: EvidenceBased Methods. Retrieved August 5, 2011, from http://kestencgreen.com/demandfor.pdf

Bartkienè, A. (1993). Rinkos kainu politika ir kainodara. Valstybinis leidybos centras. Vilnius.

Bartosevičienė, V. (2001). Ekonominè statistika. Technologija. Kaunas.
Binder, C. C. (2016). Estimation of historical inflation expectations. Explorations in Economic History, 61, 1-31. http://dx.doi.org/10.1016/j.eeh.2016.01.002

BN Vocabulary (2016). Expectations. Retrieved January 25, 2016, from http://zodynas.vz.lt/Lukesciai

Bobinaitė, V. \& Konstantinavičiūtè, I. (2012). Wholesale electricity price forecasting models: Lithuanian case. The 7th international conference on electrical and control technologies ECT-2012, Kaunas, Lithuania, May 34, 2012. Kaunas: Technologija, 2012. ISSN 1822-5934, p. 249-254.

Bonacina, M. \& Gulli, F. (2007). Electricity pricing under "carbon emissions trading": A dominant firm with competitive fringe model. Energy Policy, 35(8), 4200-4220. http://dx.doi.org/10.1016/j.enpol.2007.02.016

Catalão, J. P. S., Mariano, S. J. P. S., Mendes, V. M. F. \& Ferreira, L. A. F. M. (2007). Short-term electricity prices forecasting in a competitive market: A neural network approach. Electric Power Systems Research, 77(10), 1297-1304. http://dx.doi.org/10.1016/j.epsr.2006.09.022

Chen, S. \& Billings, S. A. (1992). Neural networks for nonlinear dynamic system modelling and identification. International Journal of Control, 56(2), 319-346. http://dx.doi.org/10.1080/00207179208934317

Chogumaira, E. N. \& Hiyama, T. (2011). Short-Term Electricity Price Forecasting Using a Combination of Neural Networks and Fuzzy Inference. Energy and Power Engineering, 3, 9-16. http://dx.doi.org/10.4236/epe.2011.31002

Chow, G. C. (2011). Usefulness of Adaptive and Rational Expectations in Economics. CEPS Working paper 221. Retrieved January 20, 2016, from https://www.princeton.edu/ gchow/Usefulness \%20of\%20\%20Adaptive\% 20and\%20Rational\%20Expectations\%20in\%20Economics\%20(2).pdf

Conejo, A. J., Javier Contreras, J., Espínola, R. \& Plazas, M. A. (2005). Forecasting electricity prices for a day-ahead pool-based electric energy market. International Journal of Forecasting, 21(3), 435-462. http://dx.doi.org/10.1016/j.ijforecast.2004.12.005

Cuaresma, J. C., Hlouskova, J., Kossmeier, S. \& Obersteiner M. (2004). Forecasting electricity spot-prices using linear univariate time-series models. Applied Energy, 77(1), 87-106. http://dx.doi.org/10.1016/S03062619(03)00096-5

de Menil, G. \& Bhalla, S. (1973). Direct Measurement of Popular Price Expectations. Econometric Research Program, Research Memorandum No. 149. Retrieved February 5, 2016, from https://www.princeton.edu/ erp/ERParchives/archivepdfs/M149.pdf

Demery, D. \& Duck, N. W. (2007). The theory of rational expectations and the interpretation of macroeconomic data. Journal of Macroeconomics, 29(1), 1-18. http://dx.doi.org/10.1016/j.jmacro.2005.02.005

Dev, P. \& Martin, M. A. (2014). Using neural networks and extreme value distributions to model electricity pool prices: Evidence from the Australian National Electricity Market 1998-2013. Energy Conversion and Management, 84, 122-132. http://dx.doi.org/10.1016/j.enconman.2014.04.012

EEX (2016). Market data of European Emission Allowances. Retrieved March 10, 2016, from https://www.eex.com/en/market-data/emissionallowances/spot-market/european-emission-allowances\#!/2016/03/10

Evans, G. W. \& Ramey, G. (2006). Adaptive Expectations, Underparameterization and the Lucas Critique. Journal of Monetary Economics, 53(2), 249-264. http://dx.doi.org/10.1016/j.jmoneco.2004.12.002

Ezekiel, M. (1938). The Cobweb Theorem. The Quarterly Journal of Economics, 52(2), 255-280. Retrieved February 5, 2016, from http://harvey.binghamton.edu/ polachek/econ_360/Ezekiel\%20QJE\%201 938\%20COBWEB.pdf

Goodwin, R. M. (1947). Dynamical Coupling with Especial Reference to Markets Having Production Lags. Econometrica, 15(3), 181-204. http://dx.doi.org/10.2307/1905478

Janeliūnas, T. \& Kasčiūnas, L. (2007). Prognozavimo metodų taikymas politikos moksluose. Politologija. 3(47), 3-43.

Johnson, M. D., Anderson, E. W. \& Fornell, C. (1995). Rational and Adaptive Performance Expectations in a Customer Satisfaction Framework. Journal of Consumer Research, 21(4), 695-707. http://dx.doi.org/10.1086/209428

Keles, D., Scelle, J., Paraschiv, F. \& Fichtner, W. (2016). Extended forecast methods for day-ahead electricity spot prices applying artificial neural networks. Applied Energy, 162, 218-230. http://dx.doi.org/10.1016/j.apenergy.2015.09.087

Keynia, F. (2012). A new feature selection algorithm and composite neural network for electricity price forecasting. Engineering Applications of Artificial Intelligence, 25(8), 1687-1697.

http://dx.doi.org/10.1016/j.engappai.2011.12.001 
Knoll, L. \& Engels, A. (2012). Exploring the Linkages between Carbon markets and Sustainable Innovations in the Energy Sector: Lessons from the EU Emissions Trading Scheme. Sustainability Innovations in the Electricity Sector. Springer-Verlag Berlin Heidelberg. http://dx.doi.org/10.1007/978-3-7908-2730-9_6

Konstantinaviciute, I. \& Bobinaite, V. (2015). Comparative analysis of carbon dioxide emission factors for energy industries in European Union countries. Renewable and Sustainable Energy Reviews, 51, 603-612. http://dx.doi.org/10.1016/i.rser.2015.06.058

Lin, W.-M., Gow, H.-J. \& Tsai, M.-T. (2010). Electricity price forecasting using Enhanced Probability Neural Network. Energy Conversion and Management, 51(12), 2707-2714 http://dx.doi.org/10.1016/j.enconman.2010.06.006

Lise, W. \& Kruseman, G. (2008). Long-term price and environmental effects in a liberalised electricity market. Energy Economics, 30(2), 230-248. http://dx.doi.org/10.1016/j.eneco.2006.06.005

Lithuanian District Heating Association (2013). Šilumos tiekimo bendroviu 2012 metu ükinès veiklos ap̌̌valga. Vilnius.

Lucas, R. E. (1976). Econometric Policy Evaluation: A Critique. CarnegieRochester Conference Series on Public Policy, 1, 19-46. http://dx.doi.org/10.1016/S0167-2231(76)80003-6

Mlambo, L. (2012). Adaptive and rational expectations hypotheses: reviewing the critiques. Journal of Economic Behavior, 2, 3-15. http://ijeb.faa.ro/download/459_MLAMBO.pdf

Moreno, M. J. J., Palmer, P. A. \& Muñoz Gracia, P. (2011). Artificial neural networks applied to forecasting time series. Psicothema, 23(2), 322-329. http://www.psicothema.com/pdf/3889.pdf

Muller, B., Reinhardt, J. \& Strickland, M. T. (1995). Neural Networks: An Introduction. 2nd updated and corrected edition. Springer-Verlag Berlin Heidelberg. http://dx.doi.org/10.1007/978-3-642-57760-4

Muth, J. F. (1961). Rational Expectations and the Theory of Price Movements. Econometrica, 29(3), 315-335. http://dx.doi.org/10.2307/1909635

Nerlove, M. (1958). Adaptive Expectations and Cobweb Phenomena. Journal of Economics, 73, 227-240. http://dx.doi.org/ 10.2307/1880597

Nord Pool Spot (2016). Historical market data. Retrieved January 15 to March 16, 2016, from http://www.nordpoolspot.com/historical-market-data/

Panapakidis, I. P. \& Dagoumas, A. S. (2016). Day-ahead electricity price forecasting via the application of artificial neural network based models. Applied Energy, 172, 132-151. http://dx.doi.org/10.1016/j.apenergy.2016.03.089

Panchal, G., Ganatra, A., Kosta, Y. P. \& Panchal, D. (2011). Behaviour Analysis of Multilayer Perceptrons with Multiple Hidden Neurons and Hidden Layers. International Journal of Computer Theory and Engineering, 3(2), 332-337. http://dx.doi.org/10.7763/IJCTE.2011.V3.328

Pearce, D. K. (1975). The Measurement of Price Expectations. Journal of Behavioral Economics, 4(1), 145-165. http://dx.doi.org/10.1016/00905720(75)90030-3

Sargent, T. J. (2008). Rational Expectations. The Concise Encyclopedia of Economics, 2nd ed. Retrieved February 6, 2016, from http://www.econlib.org/library/Enc/RationalExpectations.html

Schlueter, S. (2010). A long-term/short-term model for daily electricity prices with dynamic volatility. Energy Economics, 32(5), 1074-1081. http://dx.doi.org/10.1016/j.eneco.2010.06.008

Schwarz, H. G. \& Lang, Ch. (2006). The rise in German wholesale electricity prices: fundamental factors, exercise of market power, or both? IWE Working Paper No. 2. Institute of Economics.

Shahram Fattahi Gakieh, M. A. (2008). Modeling Inflation Expectations: The Case of Iran. Retrieved February 10, 2016, from http://sundoc.bibliothek.uni-halle.de/diss-online/08/08H147/t1.pdf

Shepherd, B. (2012). When are adaptive expectations rational? A generalization. Economics Letters, 115(1), 4-6. http://dx.doi.org/10.1016/i.econlet.2011.11.017

Singhal, D. \& Swarup, K. S. (2011). Electricity price forecasting using artificial neural networks. International Journal of Electrical Power \& Energy Systems, 33(3), 550-555. http://dx.doi.org/10.1016/j.ijepes.2010.12.009

Skribans, V. \& Balodis, M. (2016). Development of the Latvian energy sector competitiveness system dynamic model. 9th International Scientific Conference "Business and Management 2016", Vilnius, Lithuania, May 12-13, 2016. Vilnius Gediminas Technical University, 2016. http://dx.doi.org/10.3846/bm.2016.12

Tan, Z., Zhang, J., Wang, J. \& Xu, J. (2010). Day-ahead electricity price forecasting using wavelet transform combined with ARIMA and GARCH models. Applied Energy, 87(11), 3606-3610 http://dx.doi.org/10.1016/j.apenergy.2010.05.012

Tanaka, M. (2009). Transmission-constrained oligopoly in the Japanese electricity market. Energy Economics, 31(5), 690-701. http://dx.doi.org/10.1016/j.eneco.2009.03.004

Thiemer, A. (2007). Cobweb Models and Expectations. Retrieved February 10, 2016, from https://www.fh-kiel.de/fileadmin/data/wirtschaft/ Dozenten/Thiemer_Andreas/MCD/cobweb_e.pdf

Vahidinasab, V., Jadid, S. \& Kazemi, A. (2008). Day-ahead price forecasting in restructured power systems using artificial neural networks. Electric Power Systems Research, 78(8), 1332-1342. http://dx.doi.org/10.1016/i.epsr.2007.12.001

Weron, R. \& Misiorek, A. (2008). Forecasting Spot Electricity Prices: A Comparison of Parametric and Semiparametric Time Series Models. International Journal of Forecasting, 24, 744-763. http://dx.doi.org/10.1016/j.ijforecast.2008.08.004

Weron, R. (2014). Electricity price forecasting: A review of the state-of-theart with a look into the future. International Journal of Forecasting, 30(4), 1030-1081. http://dx.doi.org/10.1016/j.ijforecast.2014.08.008

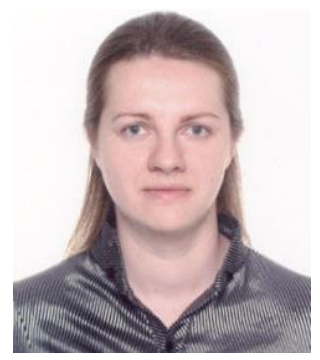

Viktorija Bobinaite received the $\mathrm{PhD}$ degree in Economics in 2012. Her research interests are energy policy, economic assessment of renewable energy, electricity pricing and price forecasting.

Since 2013, she has been an Associate Researcher at the Laboratory of Energy Systems Research of Lithuanian Energy Institute in Kaunas, Lithuania.

Phone: +370 37401950

E-mail: viktorija.bobinaite@lei.1

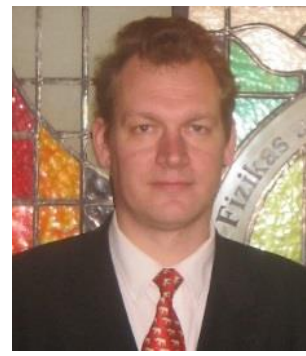

Jānis Zuters received the $\mathrm{PhD}$ degree in Computer Science in 2007. His research interests include machine learning, neural networks, and reinforcement learning.

Since 1999, he has been with the University of Latvia, Faculty of Computing (since 2011 as an Associate Professor).

Phone: +37129470187

E-mail: janis.zuters@lu.lv 